\title{
Divisive Topics as Social Threats
}

\author{
Joseph J. P. Simons \\ Institute of High Performance Computing, $A *$ STAR Singapore \\ University of North Carolina at Chapel Hill \\ Melanie C. Green \\ University at Buffalo, SUNY
}

The current work provides evidence for a psychological obstacle to the resolution of divisive social issues (e.g., affirmative action, drug legalization); specifically, people approach discussions of these issues with a threatened mindset. Across three studies, it is shown that the prospect of discussing topics which divide social opinion is associated with threatened responding (the dissensus effect). Divisive discussion topics are associated with both a greater level of self-reported threat (Studies 1 \& 3) and a greater tendency to perceive neutral faces as threatening (Study 2). Furthermore, the effect is shown to be robust across manipulations of social opinion (ratings of multiple social issues in Studies 1 \& 2; fictional polling data in Study 3), and was not reducible to individual attitude extremity (Studies 1 and 3) or a valence effect (Study 2).

Imagine you are at a party, and are conversing with some new acquaintances. Your conversation partners seem perfectly pleasant and you are all enjoying talking and getting to know one another. Then, the discussion turns to affirmative action policies. Suddenly, the interaction becomes a little tenser. The conversation does not flow quite as freely as before; people become more guarded and defensive, and maybe even find reasons to leave the conversation. Everyone breathes a little more easily when the discussion moves back toward a more consensual topic.

We argue that discussing topics on which there is no clear, widely-shared social opinion induces feelings of threat. Some attitudes are perceived to be widespread in society, such as being in favor of human rights and opposed to racial prejudice. However, for other attitude objects, there is no perceived consensual opinion. Examples include affirmative action policies, legalized abortion, and gay marriage. We propose that there is a "dissensus effect", such that discussing these divisive topics leads to feelings of threat and anxiety.

Centrally, we contend that social opinion can be a source of threat independent of its relationship to the individual's own attitude. Existing social psychological and communication theories emphasize that people are averse to divergences between their own opinions and those of others. Influential examples include the minorityopinion and spiral-of-silence literatures, which show that people are inhibited in expressing opinions which are not widely shared (e.g., Bassili, 2003; Kenworthy, Hewstone, Levine, Martin \& Willis, 2008; Morrison \& Matthes, 2011) leading to a feedback process which renders non-majority opinions increasingly invisible over time (the spiral-of-silence; Noelle-Neumann, 1993) and the homophily effect, showing people do not like to interact 
with others who hold different opinions (e.g., Byrne, 1961; Singh \& Simons, 2010). We question whether this self-other opinion conflict is necessary for feelings of threat. As a strong illustration, imagine none of the partygoers in the above example has a personal opinion on affirmative action policies. It seems plausible they will still feel threatened and anxious at discussing this divisive topic. This response would be consistent with both uncertainty reduction theory (Berger \& Calabrese, 1975) and predicted outcome value theory (Sunnafrank, 1986).

This effect has the potential to be extremely socially disruptive, due to the negative interpersonal consequences of threat. Discussion and dialogue are important mechanisms for people to learn about pressing social issues and to resolve disagreements. However, if the very discussion topic is making individuals feel threatened, these positive outcomes are unlikely to occur. Previous work has linked threat to a number of negative interpersonal behaviors, such as social distancing (Goff, Steele \& Davies, 2008) and ideological inflexibility (Nash, McGregor \& Prentice, 2011). Similarly, avoidance goals have been linked to negativity bias in interactions (Strachman \& Gable, 2006). A threat reaction to talking about divisive topics would therefore be an obstacle to social cohesion, as threatened individuals do not make good discussion partners.

\section{Social Division and Threat}

Implicit in the above discussion is a definition of divisiveness in terms of the perceived distribution of social opinion. A topic on which people perceive a particular attitude to be widespread is low in divisiveness, whereas one where there is not a clear consensual opinion is highly divisive. Operationally, we can quantify this factor in terms of the distance from an even split in opinion. A topic is maximally divisive when it splits society into two equal opinion groups (i.e., $50 \%$ are in favor and $50 \%$ are against). Conversely, divisiveness is at a minimum when there is total consensus (i.e., $100 \%$ of society is on one side and $0 \%$ are on the other).

We are deliberately using a fairly minimal definition of division, and do so with an awareness that there are most likely important moderators of these effects. For example, it is intuitive that discussing a politically-charged social issue is more anxiety-provoking than discussing an equally divisive matter of taste. Indeed, prototypical "hot button" issues may share additional features other than just divided social opinion (e.g., they may also be connected to moral values; Skitka, Bauman \& Sargis, 2005). However, in understanding this phenomenon more fully, it is beneficial to start by establishing the effect of one clearly-defined variable. Thus, our emphasis on division is simply a matter of research strategy, rather than implying that divisiveness is the only relevant causal factor.

The idea that divided social opinion would lead to feelings of threat is not only intuitively plausible, but also consistent with previous research on communication and social interaction. Namely, divisive discussion topics raise social challenges which more consensual topics do not. It is harder to anticipate an interaction partner's opinion on such topics (Berger \& Calabrese, 1975; Everly, Shih, \& Ho, 
2012) and so to tune messages to that particular partner (e.g., Echterhoff, Higgins, \& Groll, 2005; Higgins, 1992). As a result, social outcomes such as negative evaluation (Geen, 1985) and ostracism (e.g., Williams \& Nida, 2011; Zadro, Williams, \& Richardson, 2004) are more likely. Given that social belongingness has been proposed as a fundamental human need (e.g., Baumeister and Leary, 1995) and that challenges to active goals are experienced as threatening and anxiety-provoking (Nash, McGregor \& Prentice, 2011), it is to be expected that increasing the possibility of negative social outcomes would make people more anxious about the interaction. Thus, divisive topics would be expected to be more threatening both on the basis of higher interpersonal uncertainty (Berger \& Calabrese, 1975) and greater potential for poor relational outcomes (Sunnafrank, 1986). This position is also consistent with Infante \& Rancer's (1982) conception of a motivational tendency to avoid arguments.

However, a further complexity is that division may also promote interest. First, Silvia (2005) argues that interest is elicited by complex topics which exceed current comprehension. Based on this appraisal scheme, divisive issues may increase interest because the lack of agreement suggests complexity. This process of a complex topic triggering intellectual engagement is analogous to the way an opinion minority can prompt a closer consideration of arguments (conversion theory; Moscovici, 1980). Second, Infante \& Rancer's model of argumentativeness (1982) posits that there are some features of argument situations which people may find attractive - such as the opportunity to compete and defend one's position. Thus, division could trigger interest not just due to the intellectual complexity of such issues, but also for the social opportunities they provide. In light of these considerations, it is plausible that people experience a certain amount of motivational ambivalence about discussing divisive topics, feeling both threatened and interested.

\section{Relationship with previous research}

Our analysis extends existing theories on social influence in a number of ways. First, as discussed above, the dissensus effect highlights that actual self-other opinion conflict is not necessary for avoidance responses. Social division in and of itself can be a source of threat, conceptually distinct from any conflict between the individual's attitudes and those of others. Our work therefore complements not only the minority-opinion and homophily literatures referenced previously, but also research on social consensus (e.g., Clarkson, Tormala, Rucker \& Dugan, 2013) and heterogenous social audiences (Green, Visser, \& Tetlock, 2000; Visser \& Mirabile, 2004). These literatures have all traced the ways in which opinion divergence between oneself and others leads to avoidant, aversive responding. Our work, conversely, highlights that divergences between other people may be a source of threat independent of one's own opinion. In this regard, our ideas resemble Nir's concept of social ambivalence (Nir, 2005). Division can be thought of as the co-occurrence of positive and negative opinions in social groups, just as personal ambivalence is the co-occurrence of positive and negative evaluations of the same attitude object within an individual. 
Secondly, our work provides a precise specification of one central feature of controversial issues. In the current studies, we focus on divided opinion as a cause of avoidant responding. As discussed above there may also be other important features of paradigmatic controversies (e.g., moral conviction), but our analysis sets the groundwork for teasing apart these factors. In this regard, our work complements that of Chen and J. Berger (2013), who show that high levels of controversy decrease discussion of topics. While their findings are highly consistent with our theorizing, our analysis provides an important extension by conceptually breaking down the notion of 'controversy'. Chen and Berger highlight the effects of controversy, but do not examine what features distinguish controversial from non-controversial topics. Our work complements their findings by isolating the role of one key feature of controversies (namely, divided opinion).

Third, the dissensus effect draws attention to the role of ambiguity and uncertainty in social influence processes. Existing theories relate most directly to cases where opinions are clear. The minority-opinion literature is addressed to cases where there is a majority viewpoint in a group or society, and the homophily effect examines situations where people know both their own and their interlocutors' attitudes. Our work, conversely, highlights the fact that not all opinions fall within the majority / minority distinction. Divisive topics (e.g., legalized abortion, affirmative action policies) are, in our view, important precisely because there is not a consensual opinion on them. Furthermore, these cases may well be associated with a lack of personal opinion clarity and difficulty anticipating the views of others. The dissensus effect can accommodate these cases; indeed, given the causal pathways outlined above, it is in these situations of high personal and interpersonal uncertainty that it should be strongest.

\section{The current research}

The primary goal of this research is to test whether there is a dissensus effect. Do people feel more threatened by the prospect of a discussion when the topic is divisive? If so, people should show higher levels of threatrelated responses to divisive (rather than consensual) discussion topics.

\section{H1: People will report greater feelings of threat} about discussing divisive (relative to consensual) topics.

In establishing the effect, we also seek to rule out attitude extremity as a confound. Personal attitudes and perceived social opinion may be correlated. On the one hand, the complexity of divisive topics may promote attitude moderation - because people feel unsure about these topics, they hold less extreme attitudes. Conversely, the social disruptiveness of these topics may promote attitude polarization - because people anticipate conflicts about these topics, they preemptively boost their attitudes to be more extreme. For example, knowing that affirmative action policies are divisive could lead a supporter to reconsider whether they may have overlooked undesirable side-effects of the policies (attitude moderation) or to resolutely prepare to argue for their position (attitude polarization). Either mechanism would lead to a confound of divisiveness and attitude extremity (albeit in different directions). It is therefore 
important to ensure any effects of social division are not actually being driven by associated differences in attitude extremity.

H2a: Controlling for attitude extremity will not eliminate the effect of division on threat.

In addition to its role as a confound, attitude extremity may also moderate the dissensus effect. For individuals with a strong attitude, negative social outcomes may be less salient because they have the additional motivation to defend their view. Therefore, division may be less threatening to them, simply because a negative interaction would be less goalinconsistent. Testing for moderators is not a primary focus of the current research, but it seems prudent to test this possibility where data on attitudes is available.

H2b: The effect of division on threat will be stronger when attitude extremity is lower.

Second, the current research tested for the effects of social division on social perception, as measured by judgments of neutral faces. Given existing work on misattribution (e.g., Payne, Cheng, Govorun, \& Stewart, 2005), it is plausible that divisive topics will not only lead to feelings of threat, but also induce a readiness to see others as threatening. This readiness would have important social ramifications; people are unlikely to hold a calm discussion if the very topic is priming them to perceive interlocutors as threatening.

H3: Neutral faces are more likely to be seen as threatening following priming with a divisive (relative to consensual) topic.
Third (and finally), the current research tests for the motivational ambivalence hypothesized above. As previously discussed, there is reason to think division would promote interest as well as threat. The current research tests for this mixed response.

H4: People will report more interest in discussing divisive (relative to consensual) topics.

\section{Study 1: Establishing the effect}

This study provided an initial test of the dissensus effect. Participants were presented with a number of social issues. For each, they indicated their perception of social opinion, their personal attitude, and their anticipated emotions during a discussion. The primary aims of this study were threefold. First, we tested whether divisive topics were more threatening to discuss. Second, we examined the role of attitude extremity. Third, we tested for corresponding effects on interest

\section{Method}

Procedure. Participants (42 undergraduates ${ }^{1}$ ) completed an online survey, in which they viewed 60 social issues (attitude objects, given

\footnotetext{
${ }^{1}$ Participant gender was inadvertently not collected in this study. In all 3 studies, participants filled out demographic items and some individual difference measures after all experimental measures. As these were not the focus of the current discussion, they will not be mentioned further (except to give a gender breakdown of subsequent samples). Study 1 included single item measures of need for cognition, defensive confidence, extraversion, and personal need for structure. Study 2 included measures of rejection sensitivity and test anxiety. Study 3 included a measure of attachment style.
} 
Table 1.

Ratings of perceived social opinion (\% of society seen to hold positive attitudes) for 60 social issues (Study 1).

\begin{tabular}{|c|c|c|c|c|c|c|c|}
\hline \multirow{2}{*}{ Issue } & \multicolumn{3}{|c|}{ Social opinion } & \multirow{2}{*}{ Issue } & \multicolumn{3}{|c|}{ Social opinion } \\
\hline & Mean & SD & $\mathrm{n}$ & & Mean & SD & $\mathrm{n}$ \\
\hline Safe tap water & 89.49 & 17.17 & 41 & Internet pornography & 49.62 & 21.43 & 39 \\
\hline Human rights & 87.98 & 11.29 & 41 & Abortion & 48.74 & 9.87 & 42 \\
\hline Home privacy & 86.15 & 11.70 & 41 & Capital punishment & 48.24 & 14.84 & 41 \\
\hline Food safety & 85.95 & 17.70 & 41 & Endangered species & 47.82 & 27.40 & 39 \\
\hline Free speech & 83.00 & 14.16 & 41 & War in Iraq & 47.41 & 15.01 & 41 \\
\hline Supporting veterans & 80.59 & 13.59 & 41 & Gay marriage & 46.17 & 13.07 & 41 \\
\hline Safe sex & 79.07 & 15.57 & 41 & Public surveillance & 45.65 & 21.55 & 40 \\
\hline Fair pay & 78.71 & 19.55 & 41 & Nuclear weapons & 44.45 & 16.71 & 42 \\
\hline Medical confidentiality & 78.15 & 14.47 & 41 & Censorship & 44.12 & 23.26 & 41 \\
\hline Equal opportunities & 77.05 & 17.16 & 41 & Copyright piracy & 42.00 & 22.01 & 40 \\
\hline Medical licensing & 76.81 & 23.90 & 42 & Euthanasia & 40.85 & 16.96 & 41 \\
\hline Prescription safety & 75.02 & 18.65 & 41 & Nepotism & 38.79 & 18.71 & 39 \\
\hline Legal equality & 74.75 & 16.79 & 40 & Deforestation & 37.60 & 21.75 & 40 \\
\hline Gender equality & 74.05 & 17.87 & 40 & Bribery & 37.37 & 23.12 & 38 \\
\hline Recycling & 69.50 & 17.63 & 42 & Anti-gay violence & 37.33 & 22.23 & 40 \\
\hline Studying abroad & 69.46 & 15.92 & 41 & Closed-mindedness & 37.26 & 22.35 & 39 \\
\hline Upward mobility & 68.29 & 20.28 & 41 & Human cloning & 36.28 & 19.46 & 39 \\
\hline Consumer choice & 67.90 & 19.82 & 40 & Online activity tracking & 36.08 & 20.20 & 40 \\
\hline Universal suffrage & 66.51 & 23.86 & 39 & Spoiled youth & 35.42 & 20.29 & 38 \\
\hline Geriatric care & 65.46 & 20.01 & 39 & Cultural ignorance & 32.29 & 23.33 & 38 \\
\hline Immigration laws & 65.17 & 16.38 & 42 & Social segregation & 28.93 & 23.84 & 40 \\
\hline Political correctness & 60.88 & 17.99 & 42 & Teenage mothers & 26.71 & 19.84 & 41 \\
\hline Gun control & 58.61 & 15.95 & 41 & Air pollution & 26.60 & 27.83 & 35 \\
\hline Bilingual education & 55.02 & 17.73 & 42 & Poverty & 25.64 & 26.27 & 33 \\
\hline War on drugs & 54.03 & 23.66 & 40 & Racial prejudice & 25.51 & 18.82 & 37 \\
\hline Affirmative action & 53.60 & 13.61 & 40 & Childhood obesity & 22.86 & 28.53 & 36 \\
\hline Intelligent design & 53.55 & 20.97 & 40 & High unemployment & 22.19 & 32.02 & 31 \\
\hline Legalizing marijuana & 53.27 & 12.76 & 41 & Vandalism & 21.95 & 19.91 & 38 \\
\hline Health care reform & 52.44 & 18.20 & 41 & Drug addiction & 16.60 & 21.80 & 35 \\
\hline Stem cell research & 49.85 & 13.50 & 41 & Slavery & 15.16 & 26.32 & 38 \\
\hline
\end{tabular}

in Table 1). The social issues were chosen to provide a range of social opinion values. For each issue, participants were asked how much they were personally in favor (attitude position), the percentage of people who are in favor (perceived social opinion), and how much they would feel four emotions while discussing the issue with an acquaintance (threatened, anxious, interested, and relaxed). Of these four, threatened and anxious were intended to 
measure feelings of threat, interested as a measure of interest in these discussions, and relaxed as a way to ensure participants were showing differentiation in their responses (i.e., distinguishing between different emotion scales). The attitude item used a 7-point scale (anchored strongly against and strongly in favor), and the other items used 100-point scales (the "percentage in favor" social opinion item was anchored no one and everyone, and the emotion items were anchored not at all and very much so).

\section{Results}

There was a strong association between the measures of feeling threatened and anxious, consistent with them both measuring feelings of threat $(r=.77)$. Hence, the two were averaged to give a composite threat measure.

Table 2 gives descriptive statistics and zeroorder correlations for the central variables. Consistent with the concerns about confounding, there was a strong positive association between personal attitudes and social opinion -respondents were generally more personally positive towards issues they saw as more socially approved of. Table 1 also gives an issue-by-issue breakdown of perceived social opinion ratings.

Data preparation. To facilitate interpretation, some minor linear transformations were applied to the data. First, the attitude position and social opinion variables were centered on the midpoint of their respective scales, such that a value of zero represented a neutral attitude and a 50/50 split of opinion in society respectively. This centering made the analysis easier to comprehend, as the key variables in this study (i.e. social division and attitude extremity) were operationalized as deviations from these midpoints. Second, the social opinion variable was divided by 20 , so model coefficients were easier to compare. As a result, the final attitude scores ranged from -3 to +3 , and the social opinion scores from -5 to +5 . Neither of these transformations affect the inferential statistics for these variables.

Table 2.

Personal attitudes, perceived social opinion and anticipated discussion emotions from 42 participants rating 60 social issues (Study 1)

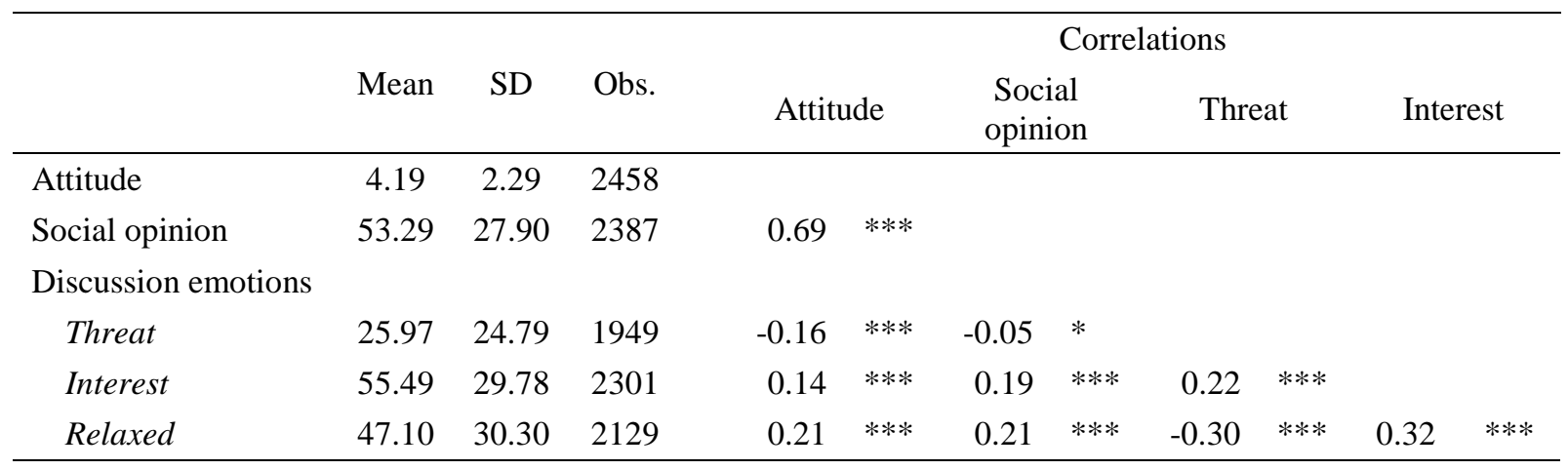

N.B. $* * * \mathrm{p}<.001 ; * * \mathrm{p}<.01 ; * \mathrm{p}<.05 ;$ Obs. $=$ number of ratings 
The degree of social division and attitude extremity were operationalized as the distance of the social opinion and attitude position variables from the midpoints of their respective scales. For social division, this procedure returns a value indicating the degree of social consensus, so the result was multiplied by -1 (so that a higher score represents more division). Therefore, the social division variable ranged from -5 (total social consensus) to 0 (a 50/50 split in opinion), and the attitude extremity variable ranged from 0 (no attitude either way) to 3 (an extreme attitude).

Analysis. The data were analyzed using a mixed-model approach. This was necessary as each participant rated multiple issues, violating the assumption of independent residuals. The mixed-model approach can accommodate this dependency within the data by explicitly allowing for individual variability in model parameters (random effects). For each of the dependent variables, a series of models were compared. Model 1 simply examined the effect of social opinion and division on emotions. Model 2 added attitude position and extremity as controls, to test whether any dissensus effect could be explained in terms of attitude extremity. Finally, Model 3 added interactions between the social opinion and attitudinal variables. This stage allows a test for the moderating effect of attitude extremity. Random effects were allowed on the intercept and all predictors in the model except interactions. To avoid convergence issues, uncorrelated random effects were estimated.

The results from the threat variable are given in Table 3. Model 1 showed a significant dissensus effect, such that more divisive topics were associated with greater feelings of threat and anxiety, $b=0.99, p=.01,95 \%$ CI[0.22, 1.77]. Model 2 showed that, far from eliminating the dissensus effect, controlling for attitude extremity actually made it stronger, $b=1.54, p$ $<.001,95 \%$ CI[0.70, 2.37]. To give a sense of magnitude, this would imply that the difference between an issue which splits society 50/50 and one which splits it $80 / 20$ is about 4.62 points on the scale, or $18.6 \%$ of a SD unit.

Finally, Model 3 provided evidence for the predicted moderating effect of attitude extremity. The dissensus effect remained significant (indicating a significant effect when attitudes were at the midpoint), $\mathrm{b}=2.13, \mathrm{p}<$ $.01,95 \%$ CI $[0.51,3.74]$. However, the effect was reduced when attitudes were more extreme, $b=-0.91, p=.02,95 \%$ CI [-1.64, -0.18]. Figure 1 plots the fixed effects in Model 3. As can be seen, neutral attitudes were associated with a dissensus effect, whereas extreme positive or negative attitudes exhibited a minority-opinion effect (whereby participants were most threatened when their opinion was not shared by most of society). ${ }^{2}$

The results for interest are given in the rightmost section of Table 3. Model 1 showed no significant effect of division, $b=-0.43, p=$ $.32,95 \%$ CI [-1.28, 0.42]. However, Model 2 revealed a positive effect when controlling for

\footnotetext{
${ }^{2}$ For threat and interest it is notable that Model 3 does not provide a large increase in fit over Model 2 (assessed using residual variance, AIC and BIC). To ensure it is appropriate to be interpreting the more complex versions, Models 2 and 3 were re-run using full information maximum likelihood estimation (FIML) and a likelihood ratio test performed. Model 3 was indeed a significantly better fit than Model 2, $\chi^{2} \mathrm{~s}(4)=15.81,17.76, p s<.01$ for threat and interest respectively.
} 
Table 3.

Effect of social opinion, social division, personal attitude, and attitude extremity on discussion emotions (Study 1)

\begin{tabular}{|c|c|c|c|c|c|c|}
\hline & \multicolumn{3}{|c|}{ Threat } & \multicolumn{3}{|c|}{ Interest } \\
\hline & Model 1 & Model 2 & Model 3 & Model 1 & Model 2 & Model 3 \\
\hline & \multicolumn{6}{|c|}{ Fixed effects } \\
\hline Intercept & $29.26 * * *$ & $27.14 * * *$ & $27.61 * * *$ & $54.08 * * *$ & $44.77 * * *$ & $47.40 * * *$ \\
\hline Social opinion (SO) & $-0.75 * *$ & 0.39 & -0.03 & $1.40 * * *$ & $0.62 \dagger$ & 0.03 \\
\hline Social division (Div) & $0.99 *$ & $1.54 * * *$ & $2.13 * *$ & -0.43 & $1.31 * *$ & $3.47 * * *$ \\
\hline Attitude (Att) & & $-2.04 * * *$ & $-1.94 * * *$ & & $1.00 * *$ & $1.25 * *$ \\
\hline Attitude extremity (Ext) & & $1.63 * *$ & 1.09 & & $6.44 * * *$ & $4.79 * * *$ \\
\hline$S O * A t t$ & & & $-0.65 * * *$ & & & $-0.56 * *$ \\
\hline$S O * E x t$ & & & -0.10 & & & 0.05 \\
\hline$D i v * A t t$ & & & -0.24 & & & -0.09 \\
\hline \multirow[t]{2}{*}{$D i v * E x t$} & & & $-0.91 *$ & & & $-1.51 * * *$ \\
\hline & \multicolumn{6}{|c|}{ Variance components } \\
\hline Intercept & 15.10 & 14.02 & 14.03 & 17.14 & 16.54 & 16.64 \\
\hline Social opinion & 0.94 & 0.84 & 0.91 & 1.43 & 1.33 & 1.37 \\
\hline Social division & 1.58 & 1.60 & 1.53 & 1.80 & 1.39 & 1.56 \\
\hline Attitude & & 0.65 & 0.70 & & 0.70 & 0.59 \\
\hline Attitude extremity & & 2.07 & 2.05 & & 3.32 & 3.24 \\
\hline \multirow[t]{2}{*}{ Residual } & 19.33 & 18.93 & 18.86 & 23.17 & 22.20 & 22.11 \\
\hline & \multicolumn{6}{|c|}{ Model information } \\
\hline AIC & 16903 & 16786 & 16783 & 20684 & 20456 & 20450 \\
\hline BIC & 16942 & 16847 & 16866 & 20724 & 20519 & 20536 \\
\hline Observations & 1908 & 1901 & 1901 & 2244 & 2236 & 2236 \\
\hline $\mathrm{N}$ & 41 & 41 & 41 & 42 & 42 & 42 \\
\hline
\end{tabular}

N.B. ${ }^{* * *} \mathrm{p}<.001 ; * * \mathrm{p}<.01 ; * \mathrm{p}<.05 ; \dagger \mathrm{p}<.10$; variance components given as standard deviations.

attitude position and extremity, $b=1.31, p<$ $.01,95 \%$ CI $[0.49,2.13]$. Hence, it seems social division may promote an approach / avoidance conflict; divisive discussion topics were associated with both more threat and more interest. Indeed, as with threat, controlling for personal attitudes makes the effect of division stronger. Finally, as with the threat variables, Model 3 showed both a significant effect of division, $b=3.47, p<.001,95 \%$ CI $[1.70,5.23]$ but also a moderating effect of attitude extremity, $b=-1.51, p<.001,95 \%$ CI [-2.31, -
0.71]. This interaction is plotted in Figure 2. As can be seen, participants were most interested in discussing divisive topics when their attitudes were neutral. However, when they held extreme attitudes, they were most interested in discussing topics on which they perceived themselves to be in a minority.

Finally, relaxation showed a different pattern of results from the other DVs, indicating that participants were showing differentiation between different emotion ratings. In Models 1 and 2 , division had a significant negative effect, 
Attitude $\cdots$ Negative - Neutral $\cdots$ Positive
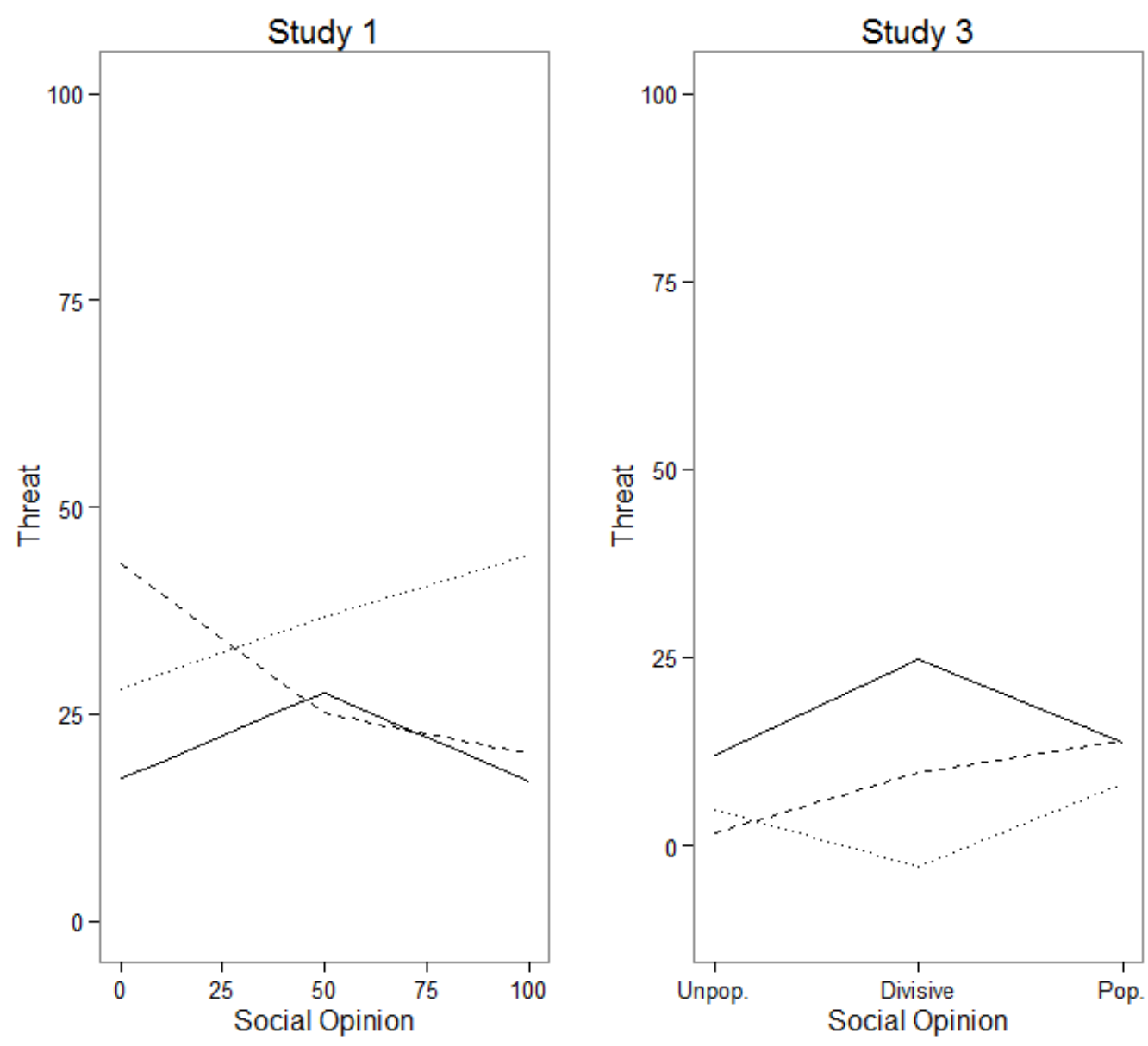

Figure 1. Effects of social opinion on self-reported threat in discussions, incorporating moderating effects of personal attitudes (lines plotted at attitude neutrality and the highest/lowest observed attitude scores).

$b \mathrm{~s}=-1.26,-1.20, p \mathrm{~s}<.01,95 \%$ CIs $[-2.07,-$ $0.44], \quad[-2.08,0.32]$ respectively, indicating divisive topics were the least relaxing to discuss. However, in Model 3 this effect became nonsignificant, $b=-0.22, p=.81,95 \%$ CI [-1.52, 1.96] and the interaction with attitude extremity was non-significant, $b=-0.38, p=.36,95 \% \mathrm{CI}$ $[-1.18,0.42]$.

\section{Discussion}

These results supported our central hypotheses. The prospect of discussing divisive topics made people feel threatened (relative to more consensual topics). This effect remained significant controlling for attitude extremity, meaning it cannot be explained in terms of confounds between division and attitude extremity. Hence, $\mathrm{H} 1$ and $\mathrm{H} 2 \mathrm{a}$ were supported. 
Attitude $\cdots$ Negative - Neutral $-\cdots$ Positive
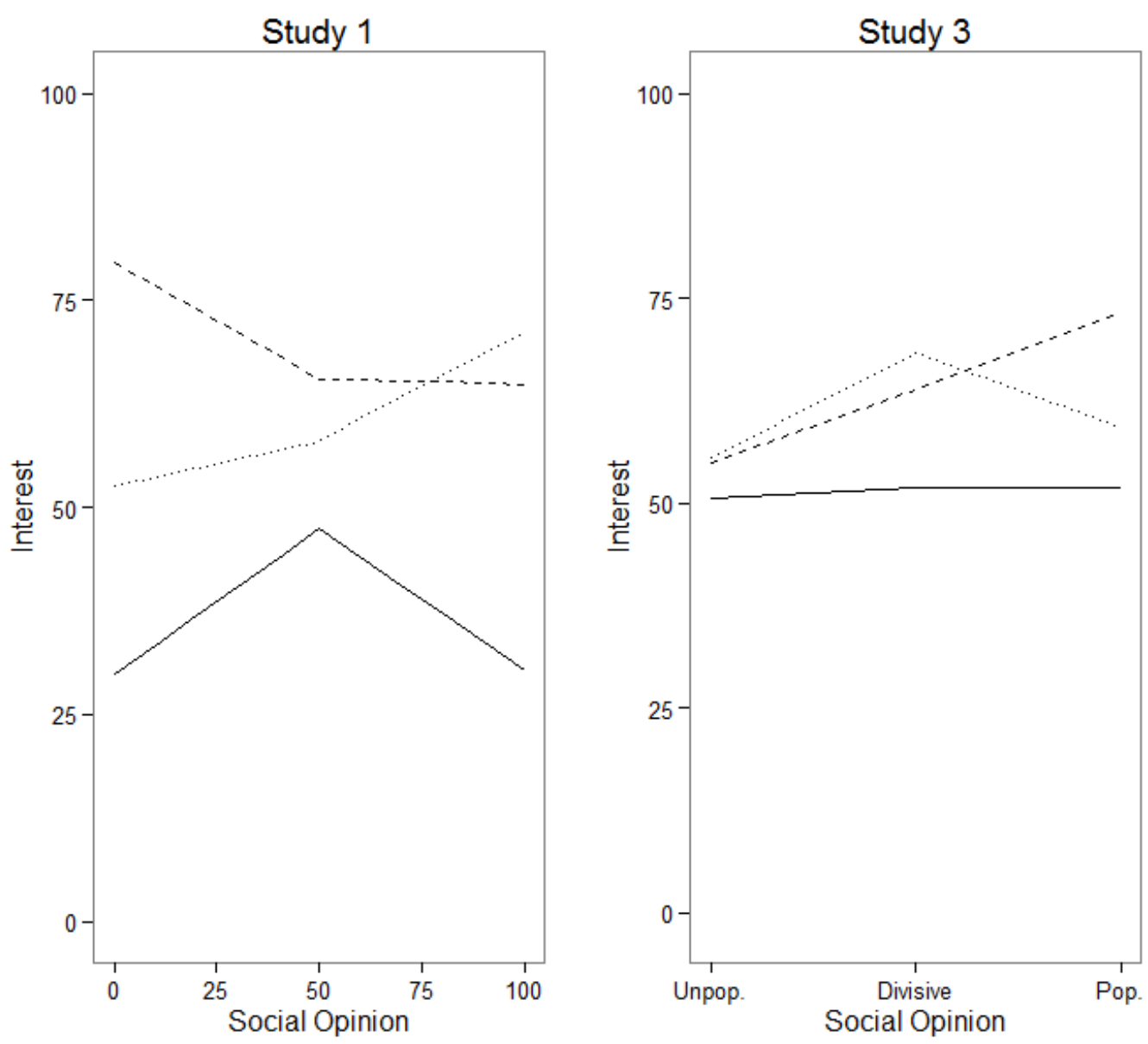

Figure 2. Effects of social opinion on self-reported interest in discussions, incorporating moderating effects of personal attitudes (lines plotted at attitude neutrality and the highest/lowest observed attitude scores).

Second, there was evidence for a moderating effect of attitude extremity. For topics on which people were personally neutral, they showed division effects across threat, and interest. However, for topics on which they held more extreme attitudes, people showed a minorityopinion effect; they were less responsive to division, and more responsive to how widely their views were shared. These findings support $\mathrm{H} 2 \mathrm{~b}$.
Third, in line with $\mathrm{H} 4$, the current results suggest that divisive discussion topics may also be more interesting than consensual topics. This result suggests there may be some degree of motivational conflict about discussing these issues. People feel threatened, but also interested.

Finally, relaxation showed a different pattern of results, indicating that participants were 
showing differentiated responses to different emotions (i.e., not just consistently rating everything higher for divisive topics).

\section{Study 2: Division makes faces seem more threatening}

Study 2 tested whether the dissensus effect has the predicted effects on social perception. We used an adaptation of the Affect Misattribution Procedure (Payne, Cheng, Govorun, \& Stewart, 2005) to examine whether threat from divisive topics would be misattributed to emotionally neutral faces. This measure was chosen for two reasons. First, it points to the important social consequences of the dissensus effect: people are unlikely to be able to have a sensible discussion if the very topic is priming them to see one another as threatening. Second, it complements the self-report DV used in Study 1 by measuring automatic reactions. Replicating the effect with this task would therefore show the dissensus effect can be detected using both explicit and implicit measures.

Given the nature of the task, we also sought to rule out a valence effect as an explanation for any effects of division. It is possible that divisive issues evoke general negative affect, and as a result facilitate all negative responses. Thus, threat attributions may be increased not due to a threat-specific mechanism, but rather due to a broader valence effect. To test for this possibility, we also measured facilitation of an unrelated negative response (unpleasantness). If effects of division can be attributed to a general valence effect, then any effect on threat should be eliminated by controlling for unpleasantness.

\section{Method}

\section{Materials.}

Issue word primes. In this study, the issue names were used as primes. Popular, unpopular, and divisive primes were selected from the issues used in Study 1 on the basis of social opinion ratings. Specifically, we used the ten highest rated as popular topics, the ten closest to the median as divisive topics, ${ }^{3}$ and the ten with the lowest ratings as unpopular topics. Of the remaining issues, six were selected for use in the practice trials; these were the two which came closest to being included in the popular, divisive, and unpopular categories (i.e., issues 11, 12, 25, 36, 58 and 59 in Table 1).

Neutral face stimuli. The face stimuli were taken from a database of pre-rated, computergenerated faces. The faces were generated using FaceGen 3.1, had no hair or other peripheral features, and were all Caucasian but a mix of male and female (see Oosterhof \& Todorov, 2008 for details). Of the 300 faces in the database, the 132 closest to the median on "threatening" ratings were used.

Issue response task. Participants completed four blocks of trials, each consisting of 33 individual trials (three practice, 30 experimental). In each trial, an issue word prime was presented for 100 $\mathrm{ms}$, followed by a $150 \mathrm{~ms}$ interval, and then a face was presented for $100 \mathrm{~ms}^{4}$ Participants

\footnotetext{
${ }^{3}$ The median was used (rather than the scale mid-point) in case the social opinion ratings in Study 1 were not centered on $50 \%$. Nine of the ten items were the same using either criterion.

${ }^{4}$ All timings are given in terms of requested times. Examination of logs revealed that actual display times achieved were close to requested timings. Over $99 \%$ of
} 
Table 4.

Misattribution of threat and unpleasantness to neutral faces across three levels of a social opinion manipulation (Study $2 ; n=53$ ).

\begin{tabular}{|c|c|c|c|c|c|c|c|c|c|c|c|c|}
\hline & \multicolumn{4}{|c|}{ UNPOPULAR } & \multicolumn{4}{|c|}{ DIVISIVE } & \multicolumn{4}{|c|}{ POPULAR } \\
\hline & \multirow{2}{*}{ Mean } & \multirow{2}{*}{$\mathrm{SD}$} & \multicolumn{2}{|c|}{$95 \% \mathrm{CI}$} & \multirow{2}{*}{ Mean } & \multirow{2}{*}{$\mathrm{SD}$} & \multicolumn{2}{|c|}{$95 \% \mathrm{CI}$} & \multirow{2}{*}{ Mean } & \multirow{2}{*}{$\mathrm{SD}$} & \multicolumn{2}{|c|}{$95 \% \mathrm{CI}$} \\
\hline & & & Lower & Upper & & & Lower & Upper & & & Lower & Upper \\
\hline Threatening & 0.39 & 0.19 & 0.34 & 0.45 & 0.41 & 0.19 & 0.36 & 0.46 & 0.33 & 0.17 & 0.28 & 0.38 \\
\hline Unpleasant & 0.54 & 0.22 & 0.48 & 0.60 & 0.54 & 0.20 & 0.49 & 0.60 & 0.47 & 0.20 & 0.41 & 0.52 \\
\hline
\end{tabular}

were then presented with a visual mask and dichotomous response option, categorizing the face as either threatening/unthreatening or pleasant/unpleasant using the $p$ and $q$ keys. The response option (threatening vs. pleasant) and the response keys (right-hand positive vs. lefthand positive) varied across blocks. The four blocks were counterbalanced across participants. Within each block, all 30 issues were presented in a random order. For each block, the three practice issues were selected randomly without replacement (and hence each occurred twice over the four blocks). Participants were instructed that, within each trial, they should ignore the first stimulus presented and only respond to the second.

Procedure. Participants (58 undergraduates; 45 female, 13 male) completed the study in a laboratory. The study was presented as investigating reactions to facial expressions. Participants completed the issue rating task, and then demographic items.

the $100 \mathrm{msec}$ displays were shown for $116-118 \mathrm{msec}$, and over $99 \%$ of the $150 \mathrm{msec}$ displays were shown for 166 $168 \mathrm{msec}$.

\section{Results}

Analyses were conducted on data from 53 participants. Five participants missed at least one block of trials and hence had to be dropped. Each participant's proportion of negative responses (i.e., threatening or unpleasant) for each prime type was calculated. Table 4 gives descriptive statistics for responses following each prime type.

To test for the predicted dissensus effect, we conducted a within-subjects analysis of variance examining the effect of prime type on threat ratings. Orthogonal contrast codes were specified to assess both the effects of social opinion (-1 / 0 / 1; unpopular / divisive / popular conditions) and social division (-0.5 / 1 / -0.5; unpopular / divisive / popular conditions). Both the social opinion and social division contrasts were significant, $F_{\mathrm{s}}(1,52)=4.67,6.63, \mathrm{ps}=$ $.04, .01 \eta^{2} \mathrm{~s}=.06, .03$ respectively. As can be seen in Table 5 , the less socially popular a topic was, the greater the threat misattributions (the significant social opinion effect). However, as predicted, divisive topics were associated with a greater level of threat misattribution than would be predicted from the opinion effect alone (the 
significant dissensus effect; estimate $=0.05$, $95 \%$ CI $[0.01,0.08])$.

To test for negative valence effects, each participant's attribution of unpleasantness for each prime type was weighted and summed to give contrast values matching those in threat. These values summarized how strongly the participant showed social opinion and social division effects in their unpleasantness ratings. These values were then mean-centered (required for control variables in a within-subjects ANOVA), and the threat ratings were reanalyzed controlling for these unpleasantness contrasts. As before, both the social opinion and social division effects were significant, $F_{S}(1$, $50)=5.71,6.62, p \mathrm{~s}=.02, .01, \eta^{2} \mathrm{~s}=.06, .03$ respectively.

\section{Discussion}

These data support H3. We found a significant dissensus effect on a face perception task, pointing to two conclusions. First, some topics are themselves capable of priming people to see one another as threatening. Second, the threat response to divisive issues can be detected with both explicit and automatic measures (such as the AMP).

Notably, the dissensus effect remained significant even when we controlled for similar trends in attributing unpleasantness, rendering an explanation in terms of a valence effect implausible. If divisiveness was simply facilitating any negative response, the effects on threat misattribution would have been eliminated by controlling for effects in unpleasantness misattribution. Our results suggest that division increases threatened responding specifically, over and above any facilitation of all negative responses.

\section{Study 3: Alternate manipulation}

The previous studies manipulated social opinion using pre-existing issues of varying levels of popularity. This strategy emphasizes the social relevance of the effect (by using salient realworld issues), and provides good statistical power (by manipulating social opinion withinsubjects). However, there are also some downsides to this approach. It is possible that there was some factor confounded with social opinion. Although we did use a range of issues and controlled for one obvious confound (personal attitude extremity), the possibility that some other factor varied with divisiveness cannot be ruled out. Relatedly, the high correlation between personal attitudes and social opinion in Study 1 may raise questions as to whether participants adequately distinguished social opinion from personal attitudes. The central aim of Study 3 was to overcome these limitations by utilizing a different manipulation. Specifically, in the current study, perceived social opinion on a given issue (direct-toconsumer drug advertising) was manipulated between-subjects by using fictitious polling data. In this manipulation, all other features of the issue are held constant except for the perceived social opinion.

\section{Methods}

\section{Materials.}

Initial attitudes. Participants rated their attitude towards direct-to-consumer-drug adverts before reading the materials below. Attitude position 
Table 5.

Personal attitude and self-reported discussion emotions across three levels of a social opinion manipulation (Study 3).

\begin{tabular}{|c|c|c|c|c|c|c|c|c|c|c|c|c|}
\hline & \multicolumn{4}{|c|}{ UNPOPULAR $(n=32)$} & \multicolumn{4}{|c|}{ DIVISIVE (n=30/32) } & \multicolumn{4}{|c|}{ POPULAR (n=31) } \\
\hline & \multirow{2}{*}{ Mean } & \multirow{2}{*}{ SD } & \multicolumn{2}{|c|}{$95 \% \mathrm{CI}$} & \multirow{2}{*}{ Mean } & \multirow{2}{*}{ SD } & \multicolumn{2}{|c|}{$95 \% \mathrm{CI}$} & \multirow{2}{*}{ Mean } & \multirow{2}{*}{$\mathrm{SD}$} & \multicolumn{2}{|c|}{$95 \% \mathrm{CI}$} \\
\hline & & & Lower & Upper & & & Lower & Upper & & & Lower & Upper \\
\hline Attitudes & 45.72 & 16.91 & 39.62 & 51.82 & 50.50 & 14.92 & 45.12 & 55.88 & 48.48 & 14.76 & 43.07 & 53.90 \\
\hline \multicolumn{13}{|c|}{ Discussion emotions } \\
\hline Threat & 8.70 & 11.57 & 4.53 & 12.87 & 17.38 & 16.82 & 11.10 & 23.66 & 12.24 & 12.29 & 7.73 & 16.75 \\
\hline Interest & 52.56 & 23.51 & 44.08 & 61.04 & 56.77 & 23.43 & 48.02 & 65.52 & 56.68 & 24.11 & 47.83 & 65.52 \\
\hline Relaxed & 59.22 & 32.35 & 47.55 & 70.88 & 52.60 & 31.79 & 40.73 & 64.47 & 61.90 & 28.68 & 51.38 & 72.42 \\
\hline
\end{tabular}

N.B. Attitudes were measured prior to the manipulation.

was rated using a 100-point scale (running from extremely bad, via neither good nor bad, to extremely good).

Social issue briefing. Participants were presented with a brief summary of the issue (i.e., whether drug companies should be allowed to advertise directly to the public). In this briefing, a sentence stated that $20 \%, 50 \%$ or $80 \%$ of people were in favor of the ads (unpopular, divisive and popular conditions respectively). To ensure that participants attended to the information, they answered three questions about the briefing (including the percentage of society in favor), after which the information was presented again. The goal of these questions was to orientate participants to the polling information - as they saw the briefing again after completing the items, their response are not informative of their final perception of social opinion.

Social issue arguments. Participants then read a short text summarizing arguments on each side of the issue. They were instructed to imagine discussing the issue with an acquaintance while reading these, and were also informed that they would be asked some comprehension questions about the arguments (explained as testing the clarity of the text). They then completed the discussion emotions questions described below.

Discussion emotions. Participants used the same scales as in Study 1 to indicate how they felt while reading the text and imagining discussing the issue.

Procedure. Participants (97 undergraduates; 36 males, 56 females, 5 unspecified) completed the study online. They initially gave their attitude on the issue (using a 100-point scale), read the issue briefing and text, and then indicated their emotions. 5

\footnotetext{
5 Participants also completed a number of measures assessing attention to and processing of the arguments. After rating their discussion emotions, participants completed seven multiple choice questions assessing text comprehension. They then rated their final attitude (using the same scale as the initial attitude measure; used to calculate a polarization score), their potential and subjective ambivalence (Priester and Petty, 1996), and their attitude certainty (Petrocelli, Tormala \& Rucker, 2007). The goal was to assess whether the dissensus effect
} 


\section{Results}

As in Study 1, the threatened and anxious discussion emotion items were positively correlated $(r=.56)$, and so averaged to give an overall threat score. Descriptive statistics by condition are given in Table 5 below. Five participants failed to complete some or all of the measures required, and hence had to be excluded from the analysis below.

Analytic strategy. The data were analyzed using regression. A series of three models were fitted to each DV. Model 1 simply regressed the DV on social opinion and division. Model 2 added attitude position and extremity. The manipulation of social opinion used in this study meant conflation of social and personal opinion was less of a concern than in previous studies, but Model 2 allows an additional statistical control against this possibility. Finally, Model 3 added the interactions between social variables (opinion and division) and attitude variables (position and extremity).

Discussion emotions. The results for threat are given in Table 6. As predicted (and consistent with our previous findings) there was a significant dissensus effect. Across Models 1, 2 and 3, participants reported feeling more threatened about discussing the topic when it was framed as socially divisive, $B \mathrm{~s}=4.61,4.28$, $7.91, p \mathrm{~s}=.03, .04, .02,95 \%$ CIs $[0.58,8.63]$, $[0.25,8.30], \quad[1.15,14.67]$ respectively.

would lead people to avoid thinking about the arguments when the issue was framed as divisive. There was some evidence for such an effect on certainty, $B=-0.45, p<$ .01 , but this was not found in any of the other measures. As these effects were not consistent and not central to the current argument, we will not discuss them further. More detailed information is available from the first author.
However, in this study, the interaction with attitude extremity was non-significant, $B=$ $2.97, \mathrm{p}=.19,95 \%$ CI $[-7.44,1.50]$. A post-hoc power analysis of Model 3 ( $n=92,8$ predictors) gave power values of $.16, .85$ and $>.99$ for small, medium, and large effects (taken as a $R^{2}$ of $.01, .09$ and .25 respectively).

The effects on the other DVs (interest, relaxation) did not replicate. The results for interest are shown in Table 6. As can be seen, while the effects were in a direction consistent with previous findings (i.e., division being associated with greater interest), they did not reach significance in the current study. With regard to relaxation, participants reported feeling more relaxed discussing topics for which they held more extreme attitudes, $B \mathrm{~s}=7.92$, $6.83, p \mathrm{~s}=0.02,0.06,95 \%$ CIs $[1.23,14.62]$, [$0.17,13.83]$ for Model 2 and 3 respectively. Aside from this, all the other effects were nonsignificant, all $p \mathrm{~s}>.25$.

\section{Discussion}

The current study extended prior findings by replicating the effect of division on threat utilizing a different (and arguably cleaner) manipulation of social opinion. These results were supportive of our argument; the dissensus effect was not only replicated, but emerged using a more direct manipulation of social opinion. The current study validates that social division is indeed a driving causal factor, as opposed to some other feature of the socially divisive issues used in Studies 1 and 2, providing further validation of $\mathrm{H} 1$ and $\mathrm{H} 2 \mathrm{a}$. Division is, therefore, a source of threat distinct from minority status (Bassilli, 2003) or 
Table 6.

Effect of social opinion, social division, personal attitude, and attitude extremity on discussion emotions (Study 3)

\begin{tabular}{|c|c|c|c|c|c|c|}
\hline & \multicolumn{3}{|c|}{ Threat } & \multicolumn{3}{|c|}{ Interest } \\
\hline & Model 1 & Model 2 & Model 3 & Model 1 & Model 2 & Model 3 \\
\hline & \multicolumn{6}{|c|}{ Regression coefficients } \\
\hline Itercept & $12.78 * * *$ & $16.41 * * *$ & $16.75 * * *$ & $55.34 * * *$ & $51.70 * * *$ & $51.45 * * *$ \\
\hline ocial opinion (SO) & 1.77 & 1.61 & 0.86 & 2.06 & 2.11 & 0.57 \\
\hline ocial division (Div) & $4.61 *$ & $4.28 *$ & $7.91 *$ & 1.43 & 1.58 & 0.42 \\
\hline ttitude (Att) & & 0.40 & 0.72 & & 0.46 & 0.42 \\
\hline ttitude extremity (Ext) & & $-2.74 \dagger$ & $-3.09 \dagger$ & & 2.86 & 3.18 \\
\hline$O * A t t$ & & & 0.62 & & & 1.05 \\
\hline$O * E x t$ & & & 0.86 & & & 1.41 \\
\hline$i v * A t t$ & & & 1.05 & & & -1.08 \\
\hline \multirow[t]{2}{*}{ iv $* E x t$} & & & -2.97 & & & 0.87 \\
\hline & \multicolumn{6}{|c|}{ Model information } \\
\hline${ }^{2}\left(\operatorname{Adj~R} R^{2}\right)$ & $0.07(0.04)$ & $0.10(0.06)$ & $0.13(0.05)$ & $0.01(-0.01)$ & $0.02(-0.03)$ & $0.03(-0.07)$ \\
\hline & 93 & 92 & 92 & 93 & 92 & 92 \\
\hline
\end{tabular}

B. $* * * p<.001 ; * * \mathrm{p}<.01 ; * \mathrm{p}<.05 ; \dagger \mathrm{p}<.10$

interpersonal disagreement (Byrne, 1961; Singh \& Simons, 2010).

However, the other effects of division were less robust than the threat effect. Study 1 had found division effects on interest and a moderating effect of attitude extremity. In the current study, these effects were in the predicted direction but failed to reach significance. Given the differences between the procedures of these two studies, these null effects are hard to interpret. On the one hand, the issue stimuli used in Study 1 may have included unknown confounds, and suffered from collinearity between attitudes and social opinion. These considerations would favour placing more faith in the current null results. On the other hand, Study 3 used a between-subjects manipulation. These manipulations are more noisy than within- studies procedures (as they combine individual differences with error variance). This leaves open the possibility that the effects are genuine, but failed to reach significance in Study 3. ${ }^{6}$

\section{General Discussion}

Together, these three studies provide evidence for our central thesis: discussing divisive issues feels threatening. Across all studies we found that discussion topics which were perceived to split social opinion led to a higher level of

\footnotetext{
${ }^{6}$ The ideal test of this possibility would be to calculate a standardized effect size with confidence interval for the effects in Study 1 and Study 3, and test whether the effect size in Study 3 fall within the interval for Study 1. Unfortunately, we are unaware of an effect size measure with well-defined confidence interval which can be calculated for both the mixed-model and regression analyses performed.
} 
threatened responding. This dissensus effect was stable across two different manipulations of social opinion and both self-report and implicit measures of threat. We were also able to rule out plausible confounds, namely attitude extremity (Studies 1 and 3) and general negativity (Study 2).

The mixed evidence for our secondary hypotheses suggests a number of directions for future research. We hypothesized that the dissensus effect should be reduced by personal attitude extremity, and that division would promote feelings of interest in addition to threat. These hypotheses address broader questions about the causal mechanism and social consequences of the dissensus effect. The current studies returned inconsistent results; while Study 1 found evidence for the effects, neither reached significance in Study 3. We propose that future research can most profitably resolve this inconsistency by addressing the broader questions of why division is threatening and how it influences people's responding.

The current studies have provided evidence for the dissensus effect, which allows future investigations to focus on why division induces threat in this manner. Probing the intervening causal pathway will yield both theoretical and practical insight. As discussed in the introduction, a plausible candidate is the increased risk of negative social outcomes when discussing divisive topics. If this causal mechanism can be established, it will have clear implications in terms of personal and situational factors which will increase the threat response (e.g., motivation to avoid social exclusion). It would also suggest ways to reduce the effect and so increase the productivity of discussion (e.g., by increasing the participants' social selfefficacy). Additionally, the focus on threat in the current theoretical framework suggests that individuals should show physiological threat reactions to dissensus situations (e.g., increased heart rate; Beatty \& Behnke, 1991). Measuring such reactions would be a useful direction for future research.

However, discussing divisive topics could also lead to positive benefits. The mechanism above emphasizes the links between division and negative social outcomes - a reasonable focus, given the consistent link between division and threatened responding. However, as Infante and Rancer (1982) highlight, there may also be a motivation to approach arguments; they offer opportunities to compete, defend one's views, and to metaphorically score points. Future work could, therefore, examine the perceived probability of positive outcomes as a potential counterbalance to the effects identified in the current paper. Furthermore, individual differences in argumentativeness may influence individuals' motivation to approach arguments (Infante \& Rancer, 1982). Future dissensus research should consider this variable as a potential moderator or control variable.

Reflecting on the causal mechanism also raises the question of attitudinal factors. On the one hand, as discussed above, if an individual cares more about maintaining their attitude position than about having a positive interaction, then they may well not be threatened by division. On the other hand, division on a minor question of taste is unlikely to cause much discomfort, whereas division on a highly-charged political topic can be a source of much anxiety. This reasoning would suggest that there are 
differential effects of the perceived attitude strength of others (which increases the dissensus effect, via increased potential for social conflict) and one's own attitude strength (which decreases the effect, via increased attitudedefense goals). It also suggests that the central attitudinal factor would be commitment to defending the attitude. In future research, this construct may be better measured by attitude importance or manipulated via goal induction, rather than indexed by attitude extremity (as in the current studies).

Turning from causes to consequences, there are a number of ways the dissensus effect may inhibit productive discussion of divisive issues. One is topic avoidance. Given that discussing divisive topics is threatening, people may avoid getting into these discussions or try to steer them to more consensual topics. This avoidance could be driven both by the individual's own anxiety, but also a reluctance to cause the same emotions in others (analogous to the role anticipated partner emotions play in Hunter and Boster's analysis of compliance-gaining behaviors; Hunter \& Boster, 1987). As with the spiral-of-silence around minority opinions, this avoidance would have negative social effects. Discussion and dialogue are important mechanisms for people to become more informed, develop more nuanced views, and negotiate compromises. If social division leads to topic avoidance, the issues which would most benefit from these discussions are being actively avoided. However, on a more optimistic note, the current studies did provide some evidence that divisive topics may be more interesting to discuss. If this effect is correct, then it suggests that people may actively seek out discussion of divisive topics if their threat responses can be addressed.

Finally, in addition to topic avoidance, divided social opinion may affect the ways people act in discussions. The findings of Study 2 testify to this; a divisive topic can lead people to categorize neutral faces as threatening. More broadly speaking, it seems plausible that division would lead to one of two consequences: either an accommodating social style aimed at avoiding conflict, or a defensive social style aimed at establishing dominance. Examining these responses and their determinants (e.g., wanting to be liked vs. be respected; Bergsieker, Shelton, and Richeson, 2010) would be informative of the ways in which discussions can descend into conflicts, as well as the downstream effects on attitude formation, consolidation, and change.

In summary, the current paper has established a robust effect linking perceived division of opinion with threatened responding in interactions. This dissensus effect has the potential to obstruct constructive discussion and so impede the resolution of difficult social issues. Discussions allow people to gain balanced viewpoints, come to understand each side, and find compromises. However, they also hold the possibility for avoidance, disagreement, and conflict. Our results demonstrate that, for many pressing issues, people will not approach discussions in the calm and open fashion required for productive dialogue. Rather, the very topic will be causing them to feel threatened and anxious. A greater understanding of the causes and consequences of this effect will, therefore, be vital in promoting greater social cohesion. 
Acknowledgements. The authors thank Lahnna Catalino and Jazmin Brown-Iannuzzi for their helpful comments on versions of this manuscript, Sy-Miin Chow for her statistical assistance, and the anonymous reviewers for their useful suggestions. Portions of this research were facilitated by a Spencer Foundation grant to Melanie Green.

\section{References}

Bassili, J. N. (2003). The minority slowness effect: subtle inhibitions in the expression of views not shared by others. Journal of Personality and Social Psychology, 84, 261. doi: 10.1037/00223514.84.2.261

Beatty, M. J., \& Behnke, R. R. (1991). Effects of public speaking trait anxiety and intensity of speaking task on heart rate during performance. Human Communication Research, 18(2), 147-176.

doi:10.1111/j.1468-2958.1991.tb00542.x

Berger, C. R., \& Calabrese, R. J. (1975). Some explorations in initial interaction and beyond: Toward a developmental theory of interpersonal communication. Human Communication Research, 1, 99112. doi: 10.1111/j.1468-2958.1975.tb00258.x

Bergsieker, H. B., Shelton, J. N., \& Richeson, J. A. (2010). To be liked versus respected: Divergent goals in interracial interactions. Journal of Personality and Social Psychology, 99, 248 - 264. doi: 10.1037/a0018474.

Baumeister, R. F., \& Leary, M. R. (1995). The need to belong: desire for interpersonal attachments as a fundamental human motivation. Psychological Bulletin, 117, 497 - 529. doi:10.1037/00332909.117.3.497

Byrne, D. (1961). Interpersonal attraction and attitude similarity. The Journal of Abnormal and Social Psychology, 62, 713-715. doi: 10.1037/h0044721

Chen, Z., \& Berger, J. (2013). When, why, and how controversy causes conversation. Journal of Consumer Research, 40, 580-593. doi:10.1086/671345

Clarkson, J. J., Tormala, Z. L., Rucker, D. D., \& Dugan, R. G. (2013). The malleable influence of social consensus on attitude certainty. Journal of Experimental Social Psychology, 49, 1019-1022. doi:10.1016/j.jesp.2013.07.001

Echterhoff, G., Higgins, E. T., \& Groll, S. (2005). Audience-tuning effects on memory: The role of shared reality. Journal of Personality and Social Psychology, 89, 257-276. doi: 10.1037/00223514.89.3.257

Everly, B. A., Shih, M. J., \& Ho, G. C. (2012). Don't ask, don't tell? Does disclosure of gay identity affect partner performance? Journal of Experimental Social Psychology, 48, 407-410. doi:10.1016/j.jesp.2011.08.005

Geen, R. G. (1985). Evaluation apprehension and response withholding in solution of anagrams. Personality and Individual Differences, 6, 293-298. doi: 10.1016/0191-8869(85)90052-2

Goff, P. A., Steele, C. M., \& Davies, P. G. (2008). The space between us: stereotype threat and distance in interracial contexts. Journal of Personality and Social Psychology, 94, 91. doi: 10.1037/00223514.94.1.91 
Green, M.C., Visser, P.S., \& Tetlock, P.E. (2000). Coping with accountability cross-pressures: Loweffort evasive tactics and high-effort quests for integrative complexity. Personality and Social Psychology Bulletin, 26(11), 1380-1391.

Higgins, E. T. (1992). Achieving 'shared reality' in the communication game: A social action that creates meaning. Journal of Language and Social Psychology, 11, 107-131. doi: $10.1177 / 0261927 X 92113001$

Hunter, J. E., \& Boster, F. J. (1987). A model of compliance-gaining message selection. Communications Monographs, 54, 63-84. doi: 10.1080/03637758709390216

Infante, D. A., \& A. S. Rancer (1982). Conceptualization and measure of argumentativeness. Journal of Personality Assessment, 46 (1), 72-80. doi: 10.1207/s15327752jpa4601_13

Kenworthy, J. B., Hewstone, M., Levine, J. M., Martin, R., \& Willis, H. (2008). The phenomenology of minority-majority status: Effects on innovation in argument generation. European Journal of Social Psychology, 38(4), 624-636. doi:10.1002/ejsp.521

Morrison, K. R., \& Matthes, J. (2011). Socially motivated projection: Need to belong increases perceived opinion consensus on important issues. European Journal of Social Psychology, 41, 707719. doi:10.1002/ejsp.797

Moscovici, S. (1980). Toward a theory of conversion behavior. Advances in Experimental Social Psychology, 13, 209-239.

Nash, K., McGregor, I., \& Prentice, M. (2011). Threat and defense as goal regulation: From implicit goal conflict to anxious uncertainty, reactive approach motivation, and ideological extremism. Journal of Personality and Social Psychology, 101, 1291-1301. doi: 10.1037/a0025944

Nir, L. (2005). Ambivalent social networks and their consequences for participation. International Journal of Public Opinion Research, 17, 422-442. doi:10.1093/ijpor/edh069

Noelle-Neumann, E. (1993). The Spiral of Silence: Public Opinion, Our Social Skin (2nd ed.). Chicago: University of Chicago Press.

Oosterhof, N. N., \& Todorov, A. (2008). The functional basis of face evaluation. PNAS Proceedings of the National Academy of Sciences of the United States of America, 105, 11087-11092. doi: 10.1073/pnas.0805664105

Payne, B. K., Cheng, C. M., Govorun, O., \& Stewart, B. D. (2005). An inkblot for attitudes: Affect misattribution as implicit measurement. Journal of Personality and Social Psychology, 89, 277-293. doi: 10.1037/0022-3514.89.3.277

Petrocelli, J. V., Tormala, Z. L., \& Rucker, D. D. (2007). Unpacking attitude certainty: Attitude clarity and attitude correctness. Journal of Personality and Social Psychology, 92, 30-41. doi: 10.1037/0022-3514.92.1.30

Priester, J. R., \& Petty, R. E. (1996). The gradual threshold model of ambivalence: Relating the positive and negative bases of attitudes to subjective ambivalence. Journal of Personality and Social Psychology, 71, 431-449. doi: 10.1037/0022-3514.71.3.431

Singh, R., \& Simons, J. J. P. (2010). Attitudes and attraction: Optimism and weight as explanations for the similarity-dissimilarity asymmetry. Social and Personality Psychology Compass, 4, 1206-1219. doi: 10.1111/j.1751-9004.2010.00328.x 
Silvia, P. J. (2005). What is interesting? Exploring the appraisal structure of interest. Emotion, 5, 89102. doi: $10.1037 / 1528-3542.5 .1 .89$

Skitka, L. J., Bauman, C. W., \& Sargis, E. G. (2005). Moral conviction: Another contributor to attitude strength or something more? Journal of Personality and Social Psychology, 88, 895. doi: 10.1037/0022-3514.88.6.895

Strachman, A., \& Gable, S. L. (2006). What you want (and do not want) affects what you see (and do not see): Avoidance social goals and social events. Personality and Social Psychology Bulletin, 32, 1446-1458. doi: 10.1177/0146167206291007

Sunnafrank, M. (1986). Predicted outcome value during initial interactions: A reformulation of uncertainty reduction theory. Human Communication Research, 13(1), 3-33. doi: 10.1111/j.14682958.1986.tb00092.x

Visser, P. S., \& Mirabile, R. R. (2004). Attitudes in the social context: the impact of social network composition on individual-level attitude strength. Journal of Personality and Social Psychology, 87, 779. doi: 10.1037/0022-3514.87.6.779

Williams, K. D., \& Nida, S. A. (2011). Ostracism: Consequences and coping. Current Directions in Psychological Science, 20, 71-75. doi: 10.1177/0963721411402480

Zadro, L., Williams, K. D., \& Richardson, R. (2004). How low can you go? Ostracism by a computer is sufficient to lower self-reported levels of belonging, control, self-esteem, and meaningful existence. Journal of Experimental Social Psychology, 40, 560-567. doi: 10.1016/j.jesp.2003.11.006 